\title{
Big Data Research on the Green Internet of Things in New Smart-Logistics
}

\author{
Tetouani Samir, Chouar Abdelsamad, Soulhi Aziz, Elalami Jamila
}

\begin{abstract}
Recent advances in information and communication technologies (ICT) have contributed to the evolution of the supply chain and logistics sector. Indeed, the analysis of massive data (Big Data) coming from smart-products makes it possible to extract enormous values for the decision-making of strategic choice: commercial or technical. But this also causes research problems because of the speed of data transmission, the huge volume, and the non-homogeneous types of data. This work provides an overview of the analysis of Big-Data $(B D)$ from the Green Internet of Things (Green-IoT) in new Smart-Logistics. This article begins with a discussion of the needs and challenges of the Green Internet of Things (Green-IoT) and Big Data (BD) analysis in logistics. Then, major data analysis technologies are examined and discussed. In addition, this article also describes future directions in this promising area.
\end{abstract}

\section{INTRODUCTION}

In this era of digitalization, technological development is fast, and the environment is characterized by uncertainty, volatility, ambiguity and complexity. To mitigate this environment, with «smart-logistics», it is necessary to analyze and use a continuous and robust innovation technology.

This work provides an overview of the analysis of BigData (BD) from the Internet of Things (IoT) in new Logistics to answers the main question: which conceptual model must be adapted then adopted for «smart-logistics»?

The paper is structured as follows. Section 2 describes the state-of-the-art technologies related to Big Data, as well as the review of IoT related surveys in order to highlight the opportunities and the challenges towards «smart-logistics». Section 3 provide a conceptual model for «smart-logistics». Section 4 concludes the review and presents the research limitations.

\section{REVIEW OF LITERATURE}

This literature review shows the state of the art on the topic «smart-logistics» and emerging technologies related to this concept. It is divided into three parts, namely: (i) Logistics concepts; (ii) Emerging technologies related to the concept of «smart-logistics»; (iii) Internet of Things (IoT); (iv) Big data analysis (BDA).

\subsection{Concept of logistics}

\footnotetext{
Revised Manuscript Received on July 18, 2019.

Tetouani Samir, Mohammed V University in Rabat, LASTIMI CELOG-ESITH, Rabat, Morocco (email: Tetouani@esith.ac.ma)

Chouar Abdelsamad, Mohammed V University in Rabat LASTIMI CELOG-ESITH, Rabat, Morocco (email: chouar@esith.ac.ma)

Soulhi Aziz, Mohammed V University in Rabat, LASTIMI ENSMR, Rabat, Morocco (email: Aziz@gmail.com)

Elalami Jamila, Mohammed V University in Rabat, LASTIMI CELOG-ESITH, Rabat, Morocco(email: j.elalami@yahoo.fr)
}

Different authors present different concepts and definitions for the logistics activity. It has adopted the most modern and widely accepted concept of the Supply Chain Management Professionals Council, which defines logistics as follows:

The part of supply chain management that effectively and inversely plans, implements, and controls the flow, and reverses the flow and storage of goods, services, and associated information between the point of origin and the point to meet the needs of customers.

\subsubsection{Evolution of logistics processes}

Logistics has undergone three revolutionary changes in the past, namely: the first change (Logistics 1.0) occurs at the end of the century. XIX and beginning of the century. $\mathrm{XX}$ with the introduction of steam mechanization on ships and trains, replacing human and animal traction as a means of transport.

The second change (Logistics 2.0) comes in the discovery of electrical energy and the introduction of mass production, which led to the automation of cargo handling in the middle of the turn of the century. XX until the end of the Second World War. The third (logistics 3.0) occurs with the systematization of logistics management and the introduction of micro-information technologies and communication technologies in the 1980s [1].

\subsubsection{Industry and «smart-logistics»}

According to [2], Industry 4.0 is characterized by the introduction of new manufacturing technologies, which enable vertically and horizontally integrated production plants, flexible processes allowing individualized mass production, intelligent machines who exchange data among themselves and control the production and logistics processes themselves. [3] points out that Industry 4.0 leads to the digitization of industrial processes. This digitization requires new logistics solutions based on emerging technologies that will affect the current transportation and management of supply chains. All of these logistics solutions are called «smart-logistics» and these solutions are a prerequisite for the existence of Industry 4.0. The existence of «smart-logistics» depends on different emerging technologies related to the ability to capture and process large amounts of data and to take action based on 


\subsection{New technologies related to «smart-logistics»}

Different emerging technologies can integrate the concept of «smart-logistics». The literature indicates that six of these technologies can be used for logistics and supply chain management: a) Internet of Things (IoT), b) Big Data Analytics (BDA), c) Cloud computing, d) Blockchain, e) 3D printing, f) crowdsourcing. Table 1 summarizes the literature review of emerging technologies related to the «smart-logistics» concept.

Table 1. Literature review of emerging technologies related to the «smart-logistics» concept

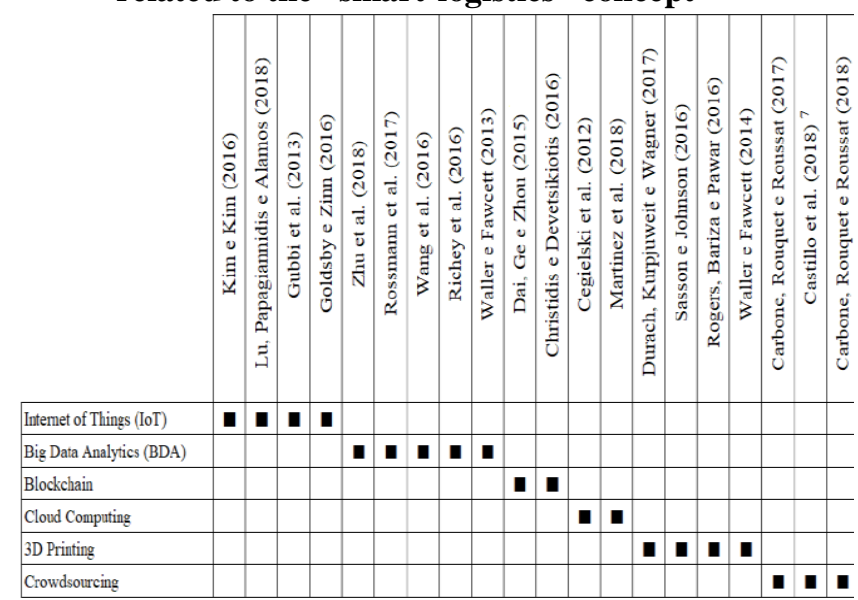

In next paragraphs we focus only on link between the three important fields: (i) Logistics, (ii) Internet of Things (IoT), and (iii) Big Data Analytics.

\subsection{Internets of Things (IoT) and Green-IoT}

According to [4] "The Internet of Things is a technological paradigm that aims to connect everything and anyone anytime, anywhere, giving rise to new services and innovative applications. [5] marks that this connection is provided by the use of a global network of interconnected objects that can be addressed exclusively using standard communication protocols.

Authors [5-8] mentioning IoT applications in logistics. According to [5], IoT technology applied to logistics is the most promising IoT application, due to its strong market potential and a significant improvement in the logistics system of the supply chain.

For [9], the Internet of Things is a concept in which the virtual world of information technologies fits perfectly into the real world of things.

According to [10], Green IoT ambitions a sustainable smart world, by lessening the energy consumption of IoT. Energy prices and carbon emissions increase drastically. Notice of environmental issues through decreasing the carbon dioxide emissions and greenhouse special effects of devices, sensors, services etc. is vital to attain a green IoT reliability and smart city applications. The continued development of Green IoT is related to green cloud computing, large data, and other advanced computing technologies [11].

The literature identifies the following IoT applications in logistics:

a) Green-Warehouse Management: [7] remarks that one of the major changes in logistics systems and supply chain the information resulting from that processing [1].

management is due to the adoption of IoT technology in warehouse management. An infrastructure of IoT provides a collaborative storage platform that facilitates the sharing of physical space and logistics information between different companies, helping them effectively track inventory, improving traceability and transparency of operations [8];

b) Green-Traffic monitoring: traffic monitoring can be carried out using GPS detection devices installed in vehicles and in constant communication via a network of IoT devices [12];

c) Green-Fleet management: fleet management is an essential element of the transport and logistics sector as it involves the movement of assets and equipment. By implementing IoT applications to manage and manage the transport and fleet, you can reduce costs and time, because IoT devices provide real-time information on fleet conditions and each vehicle [12]. Figure 1 shows how IoT technology can be integrated with fleet management.

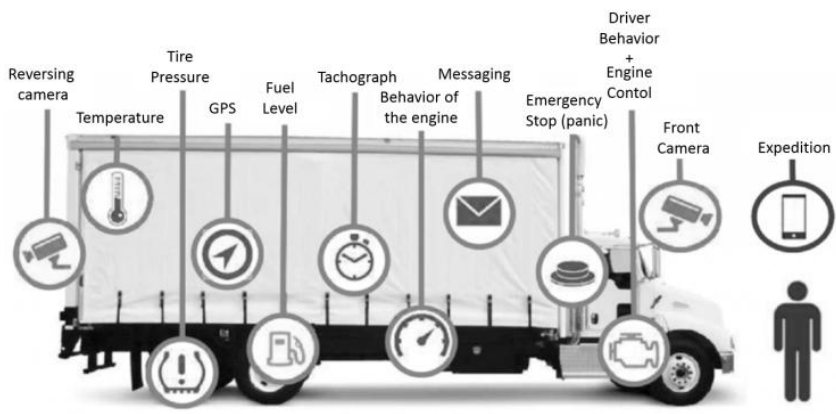

Figure 1. A truck with IoT devices connected to the internet.

d) Visibility: the transport and logistics sector depends on the correct and timely management of the supply chain. IoT technology can synchronize existing information flows and products into a supply chain, integrating data from supply chain members to provide complete and transparent information, improving the visibility and efficiency of the supply chain all members of this supply chain [14].

Figure 2 illustrates an example of supply chain visibility using IoT technology.

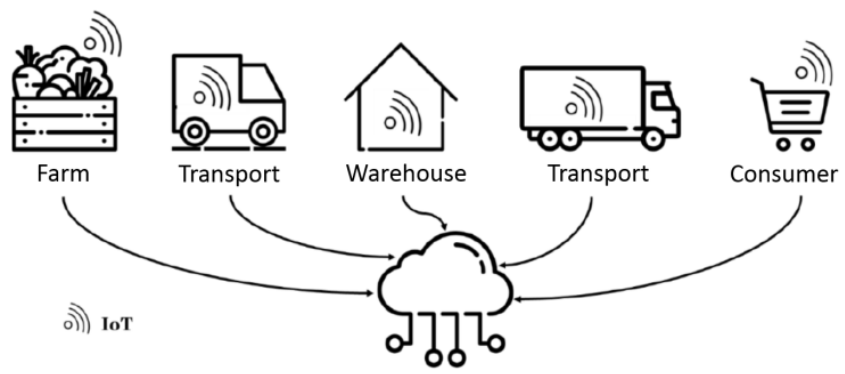

Figure 2 - Visibility of the supply chain with the use of IoT devices

\subsection{Big-Data Analysis}

The ever-growing amount of data available has created the need to develop business intelligence technologies that are summarized as large data analytics [15].

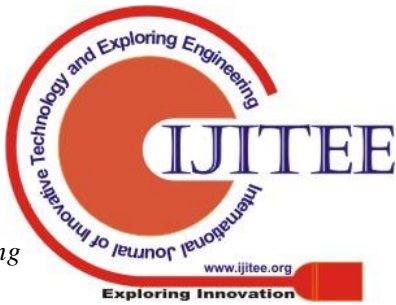


According to [16], big data can be defined as large, complex data sets with a current size of one exabyte (1018 bytes) and can reach zettabyte (1021 bytes) per year in some year's massive adoption of mobile devices, cameras, microphones and IoT devices [17].

Authors mentioning large data applications in logistics include [14] and [18-20]

[14] assures that the BDA is particularly relevant for logistics and supply chain management, as it provides the tools for decision making in increasingly global and dynamic environments. However, this same relevance creates enormous challenges for organizations that want to take advantage of massive, massive data flows, such as: market trends, customer buying patterns, maintenance cycles, and ways to reduce costs and enable more targeted business decisions [20]. [19] defines mega-data in four (4) dimensions: volume, speed, variety and veracity. A fifth dimension, called value, was added by [16] and the inclusion of this fifth dimension created the concept called "5V". The volume dimension deals with the amount of data, the speed dimension is important for decision making, the variety dimension deals with the heterogeneity of the data sources, the veracity of the dimension eliminates the invalid data, and finally the value dimension attempts to turn the big date into a global value for the organization. The BDA manages the "5V", making it possible to manage these potentially valuable new datasets using descriptive, predictive and prescriptive analyzes [21].

According to [22], descriptive analysis is more commonly used and better understood because it relies on historical data and is a source of information about what has happened and it explores this information for identify issues and opportunities within organizations' roles and processes.Predictive analytics addresses the question of what is likely to happen, by exploring data patterns using statistics, simulations, and algorithms [16]. [17] mark that predictive analytics uses quantitative and qualitative data methods to estimate, for example, stock flow and storage behavior, as well as associated costs and service levels. Incorporating predictive analytics into BDA analysis can help to identify patterns and trends and predict disturbances that may affect modes of transport.

Finally, [24] writes that prescriptive analysis involves the use of mathematical data and algorithms to determine and evaluate alternative decisions that meet the objectives and requirements characterized by high data volume and complexity, with the aim of improve business performance, competitors and gain a competitive advantage.

\section{BIG DATA AND GREEN-IOT APPLICATION FOR «SMART-LOGISTICS»\& RESULTS}

The fundamentals of «smart-logistics» are based on the traditional logistics system presented by Lambert [25] and updated to incorporate the emerging technologies cited in this literature review. Thus, the proposed model for «smartlogistics» includes the following activities and related technologies:

a) Level of service: The IoT identifies the inputs and the goods, the BDA can identify the consumption habits. b) Transport: the IoT deals with the monitoring, the inviolability and the agility of the transport, by accelerating the logistics of entry and exit;

c) Storage: IoT, and BDA can ensure that inputs and goods are stored in the places closest to the points of consumption, thus improving turnaround times;

d) Information: this new activity integrated into the model proposed by Lambert [25] is designed to manage all the complexity of data and operational, managerial and strategic information generated by this data. IoT technology provides data on the movement of goods and inputs. CSL systems streamline the delivery of inputs and goods, and all of this technology is coordinated by one or more BDA systems.

e) Stocks: Maintaining the correct inventory levels is a vital operation for the financial health of the company. According to [26], IoT-assisted BDA technology improves demand forecasting and identifies consumption patterns by sending stockouts and mitigating the "whip" effect. (Bullwhip effect), a phenomenon that generates inefficiencies in the supply chain by reacting, through a large fluctuation of stocks, to a small variation in the number of consumer orders.

f) Purchase and sale: Finally, the IoT technology allows the follow-up of the deliveries and the Internet surveillance of all the movements associated with this delivery. BDA technology manages the data and information related to this logistics operation.

The proposed model for «smart-logistics» updates the Lambert model [25] by including emerging technologies that can be used in each logistic activity and includes a new activity called "information", which coordinates all the complexity of the data and their transformation, in management information, thus collaborating with literature in the field of logistics.

\section{CONCLUSION}

This work provides an overview of the analysis of BigData (BD) from the Green-Internet of Things (Green-IoT) in new «smart-logistics». This document first introduces the concept of the new logistics. Next, enabling technologies for large data analysis are described. In addition, this document proposes a conceptual model for logistics based on the review of the existing. In addition, this document also outlines future directions and addresses open research questions. We believe that large data analytics will play an important role in promoting logistics so that it becomes an affordable reality in the near future.

\section{REFERENCES}

1. WANG, G. et al. Big data analytics in logistics and supply chain management: Certain investigations for research and applications. International Journal of Production Economics, 2016. DOI: https://doi.org/10.1016/j.ijpe.2016.03.014.

2. THOBEN, K.-D.; WIESNER, S.; WUEST, T. "Industrie 4.0" and Smart Manufacturing - A Review of Research Issues and Application Examples. International Journal of Automation Technology, v. 11, n. 1, p. 4-16, 2017. DOI: https://doi.org/10.20965/ijat.2017.p0004. 
3. LU, Y.; PAPAGIANNIDIS, S.; ALAMANOS, E. Internet of Things: A systematic review of the business literature from the user and organisational perspectives. Technological Forecasting and Social Change, v. 136, p. 285-297. 2018. DOI: https://doi.org/10.1016/j.techfore.2018.01.022.

4. DREES, J. Logistics 4.0 - tailored solutions for the future. International Press Workshop.

5. GUBBI, J. et al. Internet of Things (IoT): A vision, architectural elements, and future directions. Future Generation Computer Systems, v. 29, n. 7, p. 1645-1660, 2013. DOI: https://doi.org/10.1016/j.future.2013.01.010.

6. KIM, S.; KIM, S. A multi-criteria approach toward discovering killer IoT application in Korea. Technological Forecasting and Social Change, v. 102, p. 143-155, 2016. DOI:https://doi.org/10.1051/matecconf/201713400027.

7. GOLDSBY, T. J.; ZINN, W. Technology Innovation and New Business Models: can logistics and supply chain research accelerate the evolution? Journal of Business Logistics. v. 37, n. 2, p. 80-86. 2016.

8. LU, Y. Industry 4.0: A survey on technologies, applications and open research issues. Journal of Industrial Information Integration, v. $6, \quad$ p. 1-10. 2017. DOI: https://doi.org/10.1016/j.jii.2017.04.005.

9. UCKELMANN, D.; HARRISON, M.; MICHAHELLES, F. Architecting the Internet of Things. Architecting the Internet of Things. s. n., p. 1-24. DOI: https://doi.org/10.1007/978-3642-19157-2.

10. Zhu, C., Leung, V. C., Shu, L., \& Ngai, E. C. H. (2015). Green internet of things for smart world. IEEE Access: Practical Innovations, Open Solutions, 3, 2151-2162. doi:10.1109/ACCESS.2015.2497312

11. Albreem, M. A., El-Saleh, A. A., Isa, M., Salah, W., Jusoh, M., Azizan, M. M., \& Ali, A. (2017). Green internet of things (IoT): An overview. In: Smart Instrumentation, Measurement and Application (ICSIMA), 2017 IEEE 4th International Conference on. IEEE, 2017. p. 1-6.

12. MAJEED, M. A. A.; RUPASINGHE, T. D. Internet of things (IoT) embedded future supply chains for industry 4.0: an assessment from an ERP-based fashion apparel and footwear industry. International Journal of Supply Chain Management, v. 6, n. 1, p. 25-40, 2017.

13. ZANELLA, A et al. Internet of Things for Smart Cities. IEEE Internet of Things Journal, v. 1, n. 1, p. 22-32, 2014. DOI: https://doi.org/10.1109/JIOT.2014.2306328.

14. MACAULAY, J.; BUCKALEW, L.; CHUNG, G. Internet of Things in Logistics. DHL Trend Research, v. 1, n. 1, p. 1-27, 2015.

15. TU, M. An exploratory study of Internet of Things (IoT) adoption intention in logistics and supply chain management a mixed research approach. The International Journal of Logistics Management, s.n. p. 1-10, 2018. DOI: https://doi.org/10.1108/IJLM-11-2016-0274.

16. ROSSMANN, B. et al. The future and social impact of Big Data Analytics in Supply Chain Management: Results from a Delphi study. Technological Forecasting and Social Change, v. 130, p. 135-149. 2017. DOI: https://doi.org/10.1016/j.techfore.2017.10.005.

17. TIWARI, S.; WEE, H. M.; DARYANTO, Y. Big data analytics in supply chain management between 2010 and 2016: Insights to industries. Computers and Industrial Engineering, v. 115, p. 319-330, 2018. DOI: https://doi.org/10.1016/j.cie.2017.11.017.

18. ZHONG, R. Y. et al. Big Data for supply chain management in the service and manufacturing sectors: Challenges, opportunities, and future perspectives. Computers \& Industrial Engineering, v. 101, p. 572-591, 2016. DOI: https://doi.org/10.1016/j.cie.2016.07.013.

19. WALLER, M. A.; FAWCETT, S. E. Print a maker movement supply chain: How invention and entrepreneurship will disrupt supply chain design. Journal of Business Logistics, 2014. DOI: https://doi.org/10.1111/jbl.12045.
20. RICHEY, R. G. et al. A global exploration of Big Data in the supply chain. International Journal of Physical Distribution \& Logistics Management, v. 46, n. 8, p. 710-739, 2016. DOI: https://doi.org/10.1108/IJPDLM-05-2016-0134.

21. ZHU, S. et al. How supply chain analytics enables operational supply chain transparency: An organizational information processing theory perspective. International Journal of Physical Distribution \& Logistics Management, v. 48, n. 1, p. 47-68, 2018. DOI: https://doi.org/10.1108/IJPDLM-11-20170341.

22. WANG, K. Logistics 4.0 Solution New Challenges and Opportunities. Proceedings of the 6th International Workshop of Advanced Manufacturing and Automation. 2016. DOI: https://doi.org/10.2991/iwama-16.2016.13.

23. VASSAKIS, K.; PETRAKIS, E.; KOPANAKIS, I. Big Data Analytics: Applications, Prospects and Challenges. Mobile Big Data. v. 10, p. 3-20,2018. DOI: https://doi.org/ https://doi.org/10.1007/978-3-319-67925-9_1.

24. ZHONG, R. Y. et al. Big Data for supply chain management in the service and manufacturing sectors: Challenges, opportunities, and future perspectives. Computers \& Industrial Engineering, v. 101, p. 572-591, 2016. DOI: https://doi.org/10.1016/j.cie.2016.07.013.

25. WANG, G. et al. Big data analytics in logistics and supply chain management: Certain investigations for research and applications. International Journal of Production Economics, 2016. DOI: https://doi.org/10.1016/j.ijpe.2016.03.014.

26. LAMBERT, D. M. The Development of an Inventory Costing Methodology: a study of the costs associated with holding inventory. The Ohio State University Press, 1975.

27. HOFMANN, E. Big data and supply chain decisions: the impact of volume, variety and velocity properties on the bullwhip effect. International Journal of Production Research, v. $55, \quad$ n. 17, p. 5108-5126. 2017. DOI: https://doi.org/10.1080/00207543.2015.1061222. 